\title{
IDENTIFICATION OF CANDIDA SPP. BY PHENOTYPIC TESTS AND PCR
}

\author{
Sandra Aparecida Marinho ${ }^{1,2}$, Alice Becker Teixeira ${ }^{1}$, Otávio Silveira Santos ${ }^{1}$, Ricardo Flores Cazanova ${ }^{1}$, Carlos \\ Alexandre Sanchez Ferreira ${ }^{1}$, Karen Cherubini ${ }^{2}$, Sílvia Dias de Oliveira ${ }^{*}$ \\ ${ }^{1}$ Laboratório de Imunologia e Microbiologia, Faculdade de Biociências, Pontifícia Universidade Católica do Rio Grande do Sul, \\ Porto Alegre, RS, Brasil; ${ }^{2}$ Serviço de Estomatologia, Hospital São Lucas, Pontifícia Universidade Católica do Rio Grande do Sul, \\ Porto Alegre, RS, Brasil.
}

Submitted: January 21, 2009; Returned to authors for corrections: July 16, 2009; Approved: February 19, 2010.

\begin{abstract}
The correct identification of Candida species is of great importance, as it presents prognostic and therapeutical significance, allowing an early and appropriate antifungical therapy. The purpose of this study was to identify isolates of Candida spp. from oral mucosa of 38 patients with oral candidosis evaluated in 2004 by phenotypic methods and PCR, discriminating C. albicans from the other Candida species. The tests used for phenotypic analysis were germ-tube and chlamydoconidia production, culture in CHROMAgar ${ }^{\mathrm{TM}}$ Candida, carbohydrate assimilation test, growth at $45^{\circ} \mathrm{C}$ and culture in Tween 80 agar. Genotypic confirmation was performed by PCR. Phenotypic tests showed that $63.2 \%$ strains formed germtubes, $73.7 \%$ produced chlamydoconidia, and $63.2 \%$ showed green colonies in chromogenic medium, presumptively indicating $C$. albicans or $C$. dubliniensis. The carbohydrate assimilation test confirmed these results. A total of $21 \%$ strains were identified as $C$. krusei and $13.2 \%$ were indicative of C. tropicalis. Of these later strains, three produced chlamydoconidia. The association of other phenotypic tests with culture in Tween 80 agar identified $95.8 \%$ of strains as C. albicans and $4.2 \%$ as C. dubliniensis. All 24 strains indicative of $C$. albicans and C. dubliniensis were confirmed by PCR as C. albicans.
\end{abstract}

Key words: Candida spp. - identification - PCR - phenotypic tests

\section{INTRODUCTION}

Human pathogenic yeasts are ubiquitous in the environment (1), and some species belong to the normal human microbiota (2, 3). Candida species are usually opportunistic organisms (4), and oral candidosis ranks high in terms of incidence among the many opportunist infections observed in human immunodeficiency virus (HIV)-infected patients. $C$. albicans has long been considered the predominant etiologic agent of oral candidosis (26). Over the last decade, however, there has been an increase in the incidence of candidosis in immunocompromised individuals caused by other Candida species, such as C. glabrata, C. krusei, C. tropicalis and $C$. parapsilosis (6). In 1995, C. dubliniensis, which is a species very closely related to $C$. albicans, was identified in cases of oral candidosis in HIV-infected individuals (28). It is likely that $C$. dubliniensis strains have been and will continue to be identified as $C$. albicans, because both species share similar

*Corresponding Author. Mailing address: Faculdade de Biociências, Pontifícia Universidade Católica do Rio Grande do Sul (PUCRS), Av. Ipiranga 6681, 90619-900, Porto Alegre, Brasil.; Tel.: +55-51-33203545 Fax: +55-51-33203568.; E-mail: silviadias@ pucrs.br 
phenotypic characteristics such as formation of germ-tubes, production of chlamydoconidia in rice agar, biochemical pattern and same color of colonies on differential media CHROMagarTM Candida. C. dubliniensis is a species that can rapidly develop resistance to antifungal therapy. Therefore, patients who have received multiple treatments for fungal infections may be at increased risk of harboring C. dubliniensis as the predominant species in their oral cavities (15). If this ability of $C$. dubliniensis to develop stable fluconazole resistance in vitro also occurs rapidly in vivo, this may explain, at least in part, its recent emergence as an opportunistic pathogen in the oral cavities of HIV-infected individuals and AIDS patients, who are often treated with this drug (27).

Research in many laboratories is carried out to develop new drugs or drug delivery systems, but the development of approaches that allows quick and accurate identification of disease-causing yeasts is also necessary, especially because the incidence of human disease caused by the less common Candida species has increased.

Thus, the identification of Candida species is very important in the diagnostic laboratory, because such identification shows prognostic and therapeutical significance, allowing the early and correct antifungical therapy $(11,21)$. The purpose of this study was to identify isolates of Candida spp. by phenotypic and genotypic methods, discriminating $C$. albicans from other species of Candida.

\section{MATERIAL AND METHODS}

\section{Samples}

Samples were obtained in 2004 from 38 adult patients, female or male, with oral candidosis assisted by the Stomatology Service of São Lucas Hospital of PUCRS. The diagnosis of candidosis was established according Holmstrup and Axell (12). Patients who have used antifungal drugs were excluded from the sample. All the patients signed an informed consent form to participate in the study, which was approved by the local Ethics Committee.

The samples were collected from the oral mucosa with sterile swabs, which were rubbed on the candidosis lesion. All samples were seeded on Sabouraud dextrose agar (SDA, Merck) with chloramphenicol (16 mg/mL, Neo Química). The plates were incubated at $30^{\circ} \mathrm{C}$ for $48 \mathrm{~h}$. Each morphological colony isolate was characterized according to Milan and Zaror (21). Three colonies with characteristics of Candida sp. were inoculated individually in yeast peptone dextrose (YPD, Sigma) broth and incubated at $30^{\circ} \mathrm{C}$ for $48 \mathrm{~h}$. After this period, each culture was individually stored at $-20^{\circ} \mathrm{C}$ with $20 \%$ glycerol. Only one sample of each isolate was used for all characterizations.

\section{Germ-tube test}

Yeast cells were inoculated into $0.5 \mathrm{~mL}$ of fetal bovine serum and incubated at $37^{\circ} \mathrm{C}$ for $2.5 \mathrm{~h}$. After this period, aliquots were removed for microscopic examination (25). Germ tube was considered as a slender tube with straight walls, without septum and without constriction at the junction between the cells $(10,21)$. Germ-tube was indicative of $C$. albicans or C. dubliniensis. C. abicans ATCC 28367, C. dubliniensis CBS 7987 and C. krusei ATCC 6250 were used as reference strains.

\section{Chlamydoconidia production test}

Chlamydoconidia production test was performed using rice agar medium (10 g rice, $10 \mathrm{~g}$ bacteriological agar, and distilled water to a final adjusted volume of $1000 \mathrm{~mL}$ ) supplemented by $8 \mathrm{~mL}$ of Tween 80 . The samples previously grown in SDA were seeded as 3 parallel streaks in a rectangular piece of rice agar placed between two slides, incubated in wet chamber $(8)$ at $30^{\circ} \mathrm{C}$ for $72 \mathrm{~h}$ and visualized in an optical microscope (10X and 40X magnification) (10). The formation of rounded spores with double-wall isolates was observed as chlamydoconidia, and was indicative of $C$. albicans or C. dubliniensis (22).

\section{Chromogenic agar culture}

Each isolate was cultured on SDA at $30^{\circ} \mathrm{C}$ for $48 \mathrm{~h}$. After this, they were seeded on CHROMAgarTM Candida (Chromagar Microbiology) and incubated at $30^{\circ} \mathrm{C}$ for $48 \mathrm{~h}$. The CHROMAgar ${ }^{\mathrm{TM}}$ allows selective yeast isolation, identifying 
colonies of $C$. albicans, C. dubliniensis, C. tropicalis and $C$. krusei by morphology and color reaction (13). The strains were identified according to the manufacturer's instructions, which define $C$. albicans or $C$. dubliniensis as green colonies, $C$. tropicalis as steel blue colonies, C. krusei colonies as showing rose color and rough aspect, and the other species as developing colonies from white to rose.

\section{Carbohydrate assimilation test}

The carbohydrate assimilation test determines the ability of a yeast isolate to use a particular carbohydrate substrate as its sole carbon in a medium. Yeasts were cultured in YPD for $24 \mathrm{~h}$ at $30^{\circ} \mathrm{C}$. After, the cultures were centrifuged for $5 \mathrm{~min}$ at $2790 \mathrm{~g}$ and the pellets were washed 3 times successively, suspended in sterile saline and adjusted to 5 McFarland standard. A volume of $300 \mu \mathrm{L}$ of Yeast Nitrogen Base (YNB, Difco) and $1.5 \mathrm{~mL}$ of Candida spp. suspension were mixed to $30 \mathrm{~mL}$ of sterile bacteriological agar in Falcon tubes. The suspension was placed in $15 \mathrm{~cm}$ Petri dishes and after solidification of the medium, discs with the $2 \%$ carbohydrates (maltose, trehalose, xylose, galactose, lactose, sucrose and glucose) were placed following a guide. The suspension was incubated in $30^{\circ} \mathrm{C}$ for $96 \mathrm{~h}$, and observed daily. Glucose was used as positive control, since all the species of Candida assimilate this carbohydrate (21). The carbohydrate assimilation was observed with a presence of a halo of growth around each carbohydrate.

\section{Growth at $45^{\circ} \mathrm{C}$}

Growth at $45^{\circ} \mathrm{C}$ has been considered a useful test for the differentiation of $C$. dubliniensis (no growth) from C. albicans (growth) (23). This test was used in the 24 positive samples for the germ-tube test, for chlamydoconidia production and that developed green colonies in CHROMAgarTM.

The temperature test was performed using YPD, Brain Heart infusion (BHI, Merck), SDA and Emmons medium (2\% SDA). All samples were incubated at $45^{\circ} \mathrm{C}$, and growth was assessed daily for 10 days.

\section{Tween 80 agar}

Tween 80 agar (10 g peptone, $5 \mathrm{~g} \mathrm{NaCl}, 0.1 \mathrm{~g} \mathrm{CaCl} 2,1000$ $\mathrm{mL}$ distilled water, $5 \mathrm{~mL}$ Tween 80, $\mathrm{pH}$ 6.8) was used to evaluate the lypolityc activity of the strains (24). The samples previously cultured in SDA at $30^{\circ} \mathrm{C}$ for $24 \mathrm{~h}$, which were indicative of $C$. albicans or C. dubliniensis, were transferred to Tween 80 agar by softly touching the colony with a sterile swab perpendicularly oriented towards the agar. The cultures were incubated at $30^{\circ} \mathrm{C}$ and evaluated daily, for 5 days. Esterase production was evidenced as the presence of a halo around the site of inoculation, observed with transmitted light after 2 to 3 days, being indicative of C. albicans (24).

\section{Polymerase Chain Reaction (PCR)}

The pair of primers (5'TGTTGCTCTCTCGGGGGCGGC CG3' and 5' AGATCATTATGCCAACATCCTAGGTTAAA 3') specific for the amplification of a fragment of the RNAr gene of $C$. albicans described by Mannarelli and Kurtzman (18) was used to confirm phenotypic identification of $C$. albicans and C.dubliniensis.

For Candida DNA extraction, an aliquot of pure culture was spread on SDA and a colony was collected and inoculated into $20 \mu \mathrm{L}$ of TE buffer (10 mM Tris, $0.1 \mathrm{mM}$ EDTA, $\mathrm{pH}$ 8.0). The mixture was heated for $10 \mathrm{~min}$ in water bath at $100^{\circ} \mathrm{C}$ and, after this period, heated in microwaves at high power for 2 min.

PCR amplifications were performed in a final volume of $25 \mu \mathrm{L}$ containing $1 \mu \mathrm{L}$ of lysed yeast cell, $1.5 \mathrm{mM} \mathrm{MgCl}_{2}, 10$ $\mathrm{mM}$ Tris- $\mathrm{HCl}(\mathrm{pH}$ 8.0), $5 \mathrm{mM} \mathrm{KCl}, 1.25 \mathrm{mM}$ of each nucleotide (Amersham Biosciences), $0.02 \mathrm{mM}$ of each primer (Integrated DNA Technologies), and 1.0 U of Taq DNA polymerase (Promega). Amplifications were carried out in a MinicyclerTM Termocycler (MJ Research) using conditions modified from Mannarelli and Kurtzman (18). Reactions were as follows: initial denaturation at $94^{\circ} \mathrm{C}$ for $5 \mathrm{~min}$, followed by 35 cycles of denaturation at $94^{\circ} \mathrm{C}$ for $30 \mathrm{~s}$, annealing at $57^{\circ} \mathrm{C}$ for $1 \mathrm{~min}$ and extension at $72^{\circ} \mathrm{C}$ for $30 \mathrm{~s}$, with a final extension at $72^{\circ} \mathrm{C}$ for $4 \mathrm{~min}$. Amplification products were separated by 
electrophoresis on $2 \%$ agarose gel containing $5 \mu \mathrm{g} / \mathrm{mL}$ ethidium bromide using a 100-bp ladder (Amersham Biosciences) as molecular weight marker. All PCR used $C$. albicans ATCC 28367 as positive control and C. dubliniensis CBS 7987 as negative control.

\section{RESULTS}

A total of $63.2 \%(24 / 38)$ of strains were able to produce germ-tubes. Chlamydoconidia production was observed in $28 / 38(73.7 \%)$ of the tested strains, and 24/38 (63.2\%) showed green colonies in chromogenic medium, indicating $C$. albicans or C. dubliniensis (Table 1). To confirm these tests, the carbohydrate assimilation test was used in all 38 strains, and 24/38 (63.2\%) were indicative of C. albicans or C. dubliniensis
(Table 1). A total of 8 strains (21\%), which were able neither to form germ-tube, neither to produce chlamydoconidia, were identified as $C$. krusei by CHROMagarTM Candida and carbohydrate assimilation tests. Five strains in 38 (13.2\%) were indicative of $C$. tropicalis by the same tests. Of these 5 strains, 3 were positive for chlamydoconidia (7A, 34A and 44A), but they failed to produce germ-tube or to develop blue colonies in chromogenic agar, being thus incompatible with $C$. albicans. These results associated with carbohydrate assimilation tests indicated $C$. tropicalis as the probable species. One strain (8A) showed the ability to form germ-tube, and developed green colonies on chromogenic medium, but did not produce chlamydoconidia and was therefore classified as C. albicans. Moreover, its behavior in the carbohydrate assimilation test was compatible with this species (Table 1).

Table 1. Identification of Candida spp. by germ-tube test (GT), chlamydoconidia production test (CH), culture in CHROMAgar ${ }^{\mathrm{TM}}$ Candida and carbohydrate assimilation test (CA)

\begin{tabular}{|c|c|c|c|c|c|c|c|c|c|c|c|}
\hline \multirow[t]{2}{*}{ Strain } & \multirow[t]{2}{*}{ GT } & \multirow[t]{2}{*}{$\mathbf{C H}$} & \multirow[t]{2}{*}{ CHROMAgar TM } & \multicolumn{7}{|l|}{ CA } & \multirow{2}{*}{$\begin{array}{l}\text { Presumptiv } \\
\text { identificatio }\end{array}$} \\
\hline & & & & TRE $^{1}$ & XYL & GLU & GAL & MAL & LAC & SUC & \\
\hline $5 \mathrm{~A}$ & + & + & green & + & + & + & + & + & - & + & $\begin{array}{l}\text { C. albicans or } C \text {. } \\
\text { dubliniensis }\end{array}$ \\
\hline $6 \mathrm{~A}$ & - & - & rose & - & - & + & - & - & - & - & C. krusei \\
\hline $7 \mathrm{~A}$ & - & + & steel blue & + & + & + & + & + & - & + & C. tropicalis \\
\hline $8 \mathrm{~A}$ & + & - & green & + & + & + & + & + & - & + & $\begin{array}{l}\text { C. albicans or } C \text {. } \\
\text { dubliniensis }\end{array}$ \\
\hline $12 \mathrm{~A}$ & - & - & rose & - & - & + & - & - & - & - & C. krusei \\
\hline $13 \mathrm{~A}$ & + & + & green & + & + & + & + & + & - & + & $\begin{array}{l}\text { C. albicans or } C \text {. } \\
\text { dubliniensis }\end{array}$ \\
\hline $15 \mathrm{~A}$ & - & - & rose & - & - & + & - & - & - & - & C. krusei \\
\hline $27 \mathrm{~B}$ & + & + & green & + & + & + & + & + & - & + & $\begin{array}{l}\text { C. albicans or } C \text {. } \\
\text { dubliniensis }\end{array}$ \\
\hline $28 \mathrm{~B}$ & - & - & rose & - & - & + & - & - & - & - & C. krusei \\
\hline $33 \mathrm{~A}$ & + & + & green & + & + & + & + & + & - & + & $\begin{array}{l}\text { C. albicans or } C \text {. } \\
\text { dubliniensis }\end{array}$ \\
\hline $34 \mathrm{~A}$ & - & + & steel blue & + & + & + & + & + & - & + & C. tropicalis \\
\hline $35 \mathrm{~B}$ & + & + & green & + & + & + & + & + & - & + & $\begin{array}{l}\text { C. albicans or } C \text {. } \\
\text { dubliniensis }\end{array}$ \\
\hline $38 \mathrm{~A}$ & - & - & rose & - & - & + & - & - & - & - & C. krusei \\
\hline $40 \mathrm{~B}$ & - & - & rose & - & - & + & - & - & - & - & C. krusei \\
\hline $41 \mathrm{~A}$ & - & - & white to rose & + & + & + & + & + & - & + & Other species \\
\hline
\end{tabular}


$42 \mathrm{~A}$

$61 \mathrm{~A}$

$68 \mathrm{~A}$

$69 \mathrm{~A}$

$71 \mathrm{~A}$

$$
\begin{array}{llll}
+ & + & \text { green } \\
+ & + & \text { green } \\
- & + & \text { steel blue } \\
+ & + & \text { green } \\
- & + & \text { steel blue } \\
+ & + & \text { green } \\
& & \\
+ & + & \text { green } \\
+ & + & \text { green } \\
& & \\
- & - & \text { rose } \\
+ & + & \text { green } \\
+ & + & \text { green }
\end{array}
$$$$
\text { - } \quad \text { rose }
$$$$
+\quad+\text { green }
$$$$
-\quad+\quad \text { steel blue }
$$$$
+\quad+\text { green }
$$$$
+\quad+\text { green }
$$$$
+\quad+\text { green }
$$$$
+\quad+\quad \text { green }
$$$$
+\quad+\text { green }
$$$$
+\quad+\text { green }
$$

C. albicans ATCC $28367+\quad+\quad$ green

C. dubliniensis CBS $7987+\quad+\quad$ green

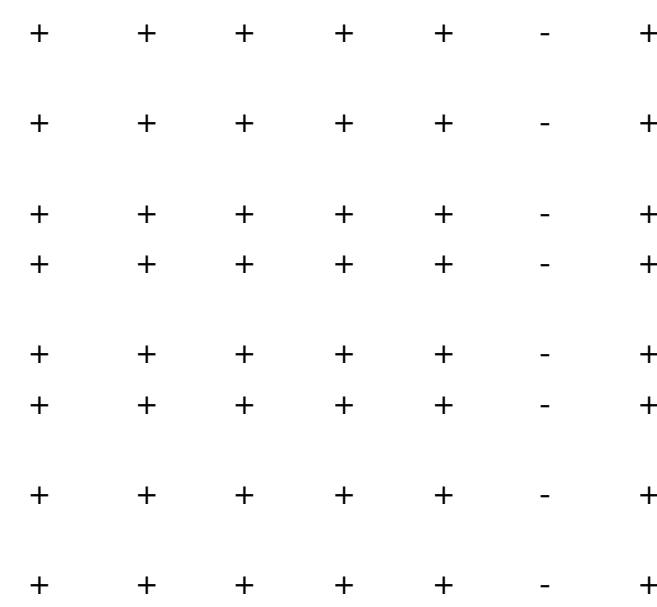
dubliniensis

C. albicans or $C$. dubliniensis

C. tropicalis

C. albicans or $C$. dubliniensis

C. tropicalis

C. albicans or $C$. dubliniensis

C. albicans or $C$. dubliniensis

C. albicans or $C$. dubliniensis

C. krusei

C. albicans or $C$. dubliniensis

C. albicans or $C$. dubliniensis

C. krusei

C. albicans or $C$. dubliniensis

C. tropicalis

C. albicans or $C$. dubliniensis

C. albicans or $C$. dubliniensis

C. albicans or $C$. dubliniensis

C. albicans or $C$. dubliniensis

C. albicans or $C$. dubliniensis

C. albicans or $C$. dubliniensis

C. albicans or $C$. dubliniensis

C. albicans or $C$. dubliniensis

C. albicans or $C$ dubliniensis

C. albicans or $C$. dubliniensis

C. dubliniensis or $C$. albicans

C. krusei 
The results obtained for reference strains using growth at $45^{\circ} \mathrm{C}$ test showed that this test was not reproducible, because a strain that grew in a culture medium at $45^{\circ} \mathrm{C}$ did not grow in a subculture in the same medium. Also, a strain grew in a culture medium at $45^{\circ} \mathrm{C}$ and did not grow in another one incubated at the same temperature. Thus, the strains isolated from patients were not tested by this assay.

Culture in Tween 80 agar identified 23/24 (95.8\%) strains as C. albicans, and only one strain (64A) as C.dubliniensis.

The PCR produced a DNA fragment of $175 \mathrm{bp}$ when tested with $C$. albicans ATCC 28367, and did not yield amplification products when the lysed cells of $C$. dubliniensis CBS 7987 were used. All 24 strains characterized phenotypically as $C$. albicans or $C$. dubliniensis were tested by PCR, being identified as C. albicans.

The phenotypic tests used in this study were not enough to identify strain $41 \mathrm{~A}$.

\section{DISCUSSION}

The phenotypic methods for the identification of Candida spp., although simple and inexpensive, impose some limitations. These methods are time-consuming and/or more often unable to discriminate $C$. albicans and $C$. dubliniensis. Therefore, the most reliable tests for rapid identification of Candida spp. and, especially, for differentiation between $C$. albicans and $C$. dubliniensis are based on molecular techniques. In the present study, all strains identified as $C$. albicans by PCR produced also germ-tubes. The germ-tube production test has the advantage to be simple and efficient in the economical and fast identification of $C$. albicans $(8,16)$. However, some results are liable to subjective interpretation, which makes necessary many repetitions, training and experience to discriminate germ-tube from pseudohyphae (6). Furthermore, although the germ-tubes cannot be quantified, a large amount is needed in a material to afford a diagnosis of $C$. albicans. Some authors evaluated sensitivity and specificity of the germ-tube test, finding results between 93 and $98.8 \%$, and between 73.3 and $100 \%$, respectively $(5,7,10)$.
Chlamydoconidia production was observed in $73.7 \%$ of strains, with three strains (7A, 34A and 44A) not being identified as $C$. albicans by other phenotypic tests and PCR. These three strains developed blue color colonies in chromogenic agar and did not produce germ-tubes, being identified as C.tropicalis, since some strains of this species can produce chlamydoconidia. The production of chlamydoconidia by isolates from $C$. dubliniensis is unusual, but when produced, chlamydoconidia are observed in abundance and often in triplets or in contiguous pairs, which can also be observed in $C$. albicans $(28,29)$. The strain $8 \mathrm{~A}$ showed the ability to form germ-tubes, behaved as $C$. albicans in CHROMagar ${ }^{\mathrm{TM}}$ medium, and showed a behavior characteristic of $C$. albicans in carbohydrate assimilation tests, but did not produce chlamydoconidia. The confirmation of this strain as C. albicans was obtained by PCR, and corroborates what described in the literature, as $10 \%$ of the strains of this species do not produce chlamydoconidia (21).

The strains that developed green colonies on CHROMagarTM Candida were identified as $C$. albicans by PCR. However, it is possible that if $C$. dubliniensis had been isolated, it would not have been discriminated from C. albicans by culture on chromogenic agar, since both species develop colonies of the same color. According to Milan and Zaror (21), there is a difference in the intensity of color of colonies between these species; $C$. albicans colonies are green-bluepale, and C. dubliniensis dark-green. Yet, it is important to observe that this ability is lost after freezing of the samples, and it did not show reproducible results (21). Furthermore, some authors described that the dark-green color on CHROMagarTM Candida as phenotypic marker for $C$. dubliniensis cannot be generally adopted as criterion, and may be limited to primary cultures [Mähnß et al. (17); Tintelnot et al. (29). Moreover, C. albicans colonies can grow sharing a variation of green color, ranging from light-green to darkgreen, depending on growth density and incubation period (10), often with the periphery of the colonies having a color distinctly different from that of the rest of the colony (26). However, Mesa et al. (20) observed that among 55 strains 
identified as $C$. albicans tested by CHROMagar ${ }^{\mathrm{TM}}$ medium, none showed the dark-green color typical of C. dubliniensis, indicating this medium as a good phenotypic criterion to differentiate both species.

The pattern of carbohydrate assimilation is considered a reliable test and is generally used for the correct identification of yeasts of clinical interest (14). The results obtained corroborated the identification of $C$. albicans or $C$. dubliniensis, C. tropicalis and C. krusei. The assimilation pattern obtained would not be useful to differentiate between C. dubliniensis and C. albicans, if the former had been isolated from patients, since the xylose was assimilated by all strains suspected of being C. albicans or C. dubliniensis.

As the phenotypic tests mentioned above were not able to discriminate $C$. albicans and $C$. dubliniensis, the growth at $45^{\circ} \mathrm{C}$ test and the observation of lipolytic activity was performed. The lipolytic activity test is simple, economical to conduct, and is easy to interpret, but it showed discrepancies as compared to the results obtained with PCR. One isolate (64A) was presumptively identified as $C$. dubliniensis, but the PCR identified this strain as $C$. albicans. An explanation for this could be the low viability of that sample, which presented problems to grow in subcultures after successive thawing. Moreover, the culture in Tween 80 agar can show lower sensitivity than PCR. The present results do not support the report of Slifkin (24), who describe that this test permitted the clear differentiation of the strains of $C$. albicans from the strains of $C$. dubliniensis within 3 days of incubation on Tween 80. The differentiation of $C$. albicans from $C$. dubliniensis by growth at $45^{\circ} \mathrm{C}$ was not reproducible and showed conflicting results; therefore, the test could not be used for the differentiation between these species in the present study, as already indicated by Gales et al. (9). These authors showed that none of 66 C. dubliniensis isolates was able to grow at $45^{\circ} \mathrm{C}$, and 23 out of 100 C. albicans isolates were not able to grow at this temperature. This demonstrates that this test offers low specificity, and that $C$. albicans isolates could be falsely identified as C. dubliniensis. However, Pinjon et al. (23) describe this test as simple, reliable, inexpensive, reproducible, and readily applicable to large numbers of isolates.

The differentiation between $C$. albicans and $C$. dubliniensis remains a challenge for clinical microbiology laboratories. The most pronounced differences between these species are genetic, where C. dubliniensis is approximately $2.5 \%$ divergent from the $C$. albicans DNA sequence, as determined by DNA fingerprinting, karyotype analysis, and DNA sequence analysis of rRNA genes $(17,27)$. Sequence differences between $C$. albicans and $C$. dubliniensis have been potentially exploited in the design of oligonucleotide primers used in PCR, an approach which is increasingly being used in clinical laboratories. In this study, all $24 C$. albicans or $C$. dubliniensis presumptively identified by phenotypic methods were confirmed as $C$. albicans by PCR using oligonucleotide primers specific for this species. The advantages of PCR include reproducibility, high sample volume throughput (27), relatively short processing time, high sensitivity and specificity, ability to detect low levels of yeasts from minimal sample volumes (30), ease to perform and it is available to most laboratories (18). The PCR procedure described here allowed the identification of $C$. albicans in less than 1 day, using a simple technique for obtaining DNA, using boiling and heating in microwaves, which helps to turn this method inexpensive, as commercial kits for DNA extraction are not necessary.

No single phenotypic test has proven to be highly effective in the distinction between $C$. albicans and $C$. dubliniensis, and genotypic tests may be necessary for definitive identification. The combination of some phenotypic methods can be useful for the presumptive identification of these species, but they would require a pure culture and 3-5 days or longer for a differentiation between $C$. albicans and $C$. dubliniensis isolates. Molecular methods can give definitive identification with one-day results and do not need previous cultures. Thus, the diagnostic can be made directly from the material collected from patients, providing valuable information for patient management. 


\section{ACKNOWLEDGEMENTS}

S. A. Marinho received a scholarship from Conselho Nacional de Desenvolvimento Científico e Tecnológico (CNPq). Financial support was provided by $\mathrm{CNPq}$.

\section{REFERENCES}

1. Aheam, D.G. (1998). Yeasts pathogenic for humans. In: Kurtzman, C.P. \& Fell, J.W. (eds) The yeasts, a taxonomic study. Amsterdam: Elsevier Science, 9-14.

2. Beighton, D.; Ludford, R.; Clark, D.T. et al. (1995). Use of CHROMagar Candida medium for isolation of yeasts from dental samples. J Clin Microbiol 33: 3025-7.

3. Budtz-Jörgensen, E. (1990). Etiology, pathogenesis, therapy, and prophylaxis of oral yeast infections. Acta Odontol Scand 48: 61-9.

4. Budtz-Jörgensen, E. (1990). Histopathology, immunology, and serology of oral yeast infections. Diagnosis of oral candidosis. Acta Odontol Scand 48: 37-43.

5. Campbell, C.K.; Holmes, A.D.; Davey, K.G.; Szekely, A.; Warnock, D.W. (1998). Comparison of a new chromogenic agar with the germ tube method for presumptive identification of Candida albicans. Eur J Clin Microbiol Infec Dis 17: 367-8.

6. Carrillo-Muñoz, A.J.; Quindós, G.; Cárdenes, C.D. et al. (2001). Evaluation of Chromalbicans Agar for presumptive identification of Candida albicans. Rev Iberoam Micol 18: 105-8.

7. Conceição, G.C.; Coelho, P.P.; Sousa Junior, M.A.; Pereira, M.L.; Miguel, D.S.C.G.; Toralles, M.B.P. (2005). Avaliação do teste tubo germinativo em secreção vaginal a fresco para triagem de Candida albicans: um teste rápido. Newslab 73: 106-12.

8. Fisher, F.; Cook, N. (1998). Reagents, stains, media and methods. In: Fisher, F. \& Cook, N. (eds) Fundamentals of diagnostic mycology. Saunders, 320-340.

9. Gales, A.C.; Pfaller, M.A.; Houston, A.K. et al. (1999). Identification of Candida dubliniensis based on temperature and utilization of xylose and B-methyl -D-glucoside as determined with the API 20C AUX and Vitek YBC systems. J Clin Microbiol 37: 3804-8.

10. Gatica, J.L.M.; Goic, I.B.; Martinez, M.A.T. et al. (2002). Utilidad del agar cromocandida para el diagnostico diferencial de Candida spp aisladas de muestras vaginales. Rev Chil Obstet Ginecol 67: 300-4.

11. Godoy, P.; Almeida, L.P.; Colombo, A.L. (2001). Identificación de Candida albicans utilizando el medio cromogénico Albicans ID. Rev Iberoam Micol 18: 197-9.

12. Holmstrup, P.; Axéll, T. (1990). Classification and clinical manifestations of oral yeast infections. Acta Odontol Scand 48: 57-9.

13. Hospenthal, D.R.; Beckius, M.L.; Floyd, K.L.; Horvath, L.L.; Murray, C.K. (2006). Presumptive identification of Candida species other than $C$. albicans, C. krusei and C. tropicalis with the chromogenic medium CHROMagar Candida. Ann Clin Microbiol Antimicrob 5: 1-5.

14. Hussain Qadri, S.M.; Nichols, C.W. (1978). Tube carbohydrate assimilation method for the rapid identification of clinically significant yeasts. Med Microbiol Immunol 165: 19-27.

15. Jabra-Rizk, M.A.; Baqui, A.; Kelley, J.I.; Falkler, W.A.Jr.; Merz, W.G.; Meiller, T.F. (1999). Identification of Candida dubliniensis in a prospective study of patients in the United States. J Clin Microbiol 37: 321-6.

16. Lacaz, C.S.; Porto, E.; Martins, J.E.C. et al. (2002). Leveduras de interesse médico. In: Lacaz, C.S., Porto, E., Martins, J.E.C, VaccariHeins, E.M., De Melo, N.T. (eds) Tratado de Micologia Médica. São Paulo: Sarvier, 123-73.

17. Mähnß, B.; Stehr, F.; Schäfer, W.; Neuber, K. (2005). Comparison of standard phenotypic assays with a PCR method to discriminate Candida albicans and C. dubliniensis. Mycoses 48: 55-61.

18. Mannarelli, B.M.; Kurtzman, C.P. (1998). Rapid identification of Candida albicans and other human pathogenic yeasts by using short oligonucleoides in a PCR. J Clin Microbiol 36: 1634-41.

19. Martins, C.A.P.; Koga-Ito, C.Y.; Jorge, A.O.C. (2002). Presence of Staphylococcus spp. and Candida spp. in the human oral cavity. Braz J Microbiol 33: 236-40.

20. Mesa, L.M.; Arcaya, N.; Cañas, O.; Machado, Y.; Calvo, B. (2004). Evaluación de los caracteres fenotípicos para diferenciar Candida albicans de Candida dubliniensis. Rev Iberoam Micol 21: 135-8.

21. Milan, E.P.; Zaror, L. (2004). Leveduras: identificação laboratorial. In: Sidrim, J.J.C. \& Rocha, M.F.G. (eds) Micologia Médica à luz de autores contemporâneos. Rio de Janeiro: Guanabara Koogan, 89-101.

22. Paula, C.C. (1998). Candidíases. In: Zaitz, C., Campbell, I., Marques, A.S., Ruiz, L.R., Souza, V.M. (eds) Compêndio de micologia médica. Rio de Janeiro: Medsi, 99- 107.

23. Pinjon, E.; Sullivan, D.; Salkin, I.; Shanley, D.; Coleman, D. (1998). Simple, inexpensive, reliable method for differentiation of Candida dubliniensis from Candida albicans. J Clin Microbiol 36: 2093-95.

24. Slifkin, M. (2000). Tween 80 test responses of various Candida species. J Clin Microbiol 38: 4626-28.

25. Souza, V.M. (1998). Técnicas laboratoriais utilizadas em micologia médica. In: Zaitz, C.; Campbell, I.; Marques, A.S.; Ruiz, L.R.; Souza, V.M. (eds) Compêndio de micologia médica. Rio de Janeiro: Medsi 5163.

26. Stenderup, A. (1998). Oral mycology. Acta Odontol Scand 1990; 48: 310.

27. Sullivan D, Coleman D. Candida dubliniensis: characteristics and identification. J Clin Microbiol 36: 329-34.

28. Sullivan, D.; Westerneng, T.J.; Haynes, K.A.; Bennett, D.E.; Coleman, D.C. (1995). Candida dubliniensis:sp. nov.: phenotypic and molecular characterization of a novel species associated with oral candidosis in HIV-infected individuals. Microbiology 141: 1507-21.

29. Tintelnot, K.; Haase, G.; Seibold, M. et al. (2000). Evaluation of 
phenotypic markers for selection and identification of Candida dubliniensis. J Clin Microbiol 38: 1599-608.

30. Wahyuningsih, R.; Freisleben, H.J.; Sonntag, H.G.; Schnitzler, P. (2000).
Simple and rapid detection of Candida albicans DNA in serum by PCR for diagnosis of invasive candidiasis. J Clin Microbiol 38: 3016-21. 